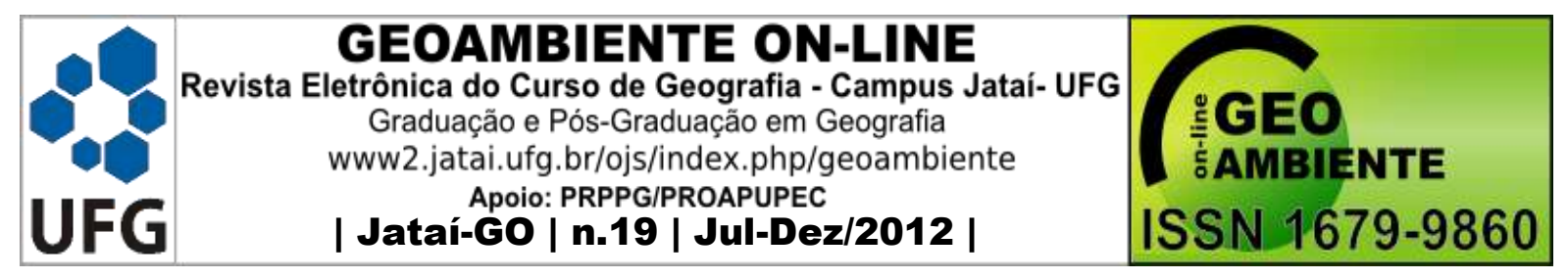

\title{
CONTRIBUIÇÕES DO MÉTODO GEOSSISTÊMICO AOS ESTUDOS INTEGRADOS DA PAISAGEM
}

\author{
Anizia Oliveira ${ }^{1}$, Rosemeri Melo e Souza ${ }^{2}$
}

(1 - Universidade Federal de Sergipe, Doutoranda e Mestre em Geografia pelo NPGEO/UFS. Pesquisadora do Grupo de Pesquisa em Geoecologia e Planejamento Territorial/GEOPLAN/UFS/CNPq, aniziacaoliveira@gmail.com, 2 - Universidade Federal de Sergipe, Prof ${ }^{a}$ Pós Doutora Associada dos Cursos de Graduação e Pós-Graduação em Geografia da Universidade Federal de Sergipe DGE/NPGEO/UFS e do Curso de Mestrado e Doutorado do PRODEMA, Coordenadora do Grupo de Pesquisa em Geoecologia e Planejamento Territorial/GEOPLAN/UFS/CNPq e Bolsista em Produtividade em Pesquisa do CNPq. rosemerimeloesouza@gmail.com).

\section{Resumo}

O presente artigo objetiva exprimir, com base na discussão sobre a paisagem e na reflexão sobre questões teórico-metodológicas de análise, a relevância para a Geografia Física da perspectiva geossistêmica na condução de estudos integrados. Mediante uma breve trajetória sobre o desenvolvimento do conceito de paisagem, partindo de Humboldt até os dias atuais, e tendo como base a contribuição de diversas escolas, foi possível discutir a importância da compreensão dos fenômenos geográficos a partir da uma abordagem integradora.

Palavras-chave: paisagem, geossistema, geografia física

\section{Abstract \\ CONTRIBUTIONS OF THE GEOSYSTEM TO THE STUDY INTEGRATED OF THE LANDSCAPE}

This article will provide a brief history of the development of the concept of aiming landscape, based on reflection on the theoretical and methodological analysis, the relevance to the physical geography of the systemic approach in conducting integrated studies. Through a historical overview on the development of the concept of landscape from Humboldt until the

\footnotetext{
Artigo recebido para publicação em 20 de Setembro de 2012
} Artigo aprovado para publicação em 12 de Dezembro de 2012 


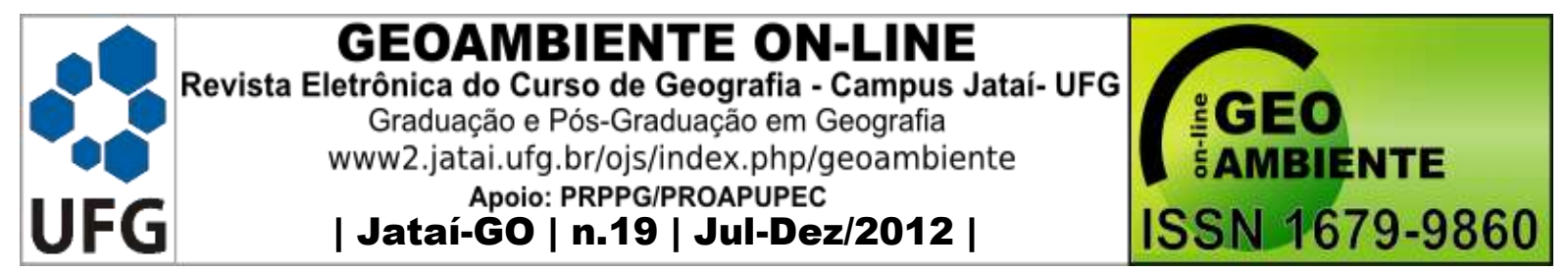

present day and based on the contribution from various schools was possible to discuss the importance of the understanding the geographic phenomena from an integrative of the landscape approach.

Key words: landscape, geosystem, physical geography

\section{Resumen}

CONTRIBUCIONES DEL AL MÉTODO GEOSSISTÊMICO PARA ESTUDIOS INTEGRADO DEL PAISAJE

En este artículo se pretende expresar, en base a la discusión del paisaje y la reflexión sobre temas de análisis teórico y metodológico, la relevancia de la perspectiva geossistêmica en la realización de estudios integrados de la geografía física. Através de una breve historia del desarrollo del concepto de paisaje, desde Humboldt up actualidad, y con base en las aportaciones de las diversas escuelas, fue posible para discutir la importancia de la comprensión de los fenómenos geográficos desde un enfoque integrador.

Palabras clave: geosistema, paisaje, la geografía física

\section{INTRODUÇÃO}

A origem e o desenvolvimento do conceito de paisagem atrelam-se à construção de teorias e métodos de pesquisa centrados em inúmeras perspectivas de análise. Ao longo do tempo, a paisagem adquire vários significados, os conceitos e métodos se diversificam e os estudos passam da abordagem restrita à análise dos componentes biofísicos para a perspectiva que se preocupa, no contexto das abordagens analítico-integradas, com o complexo de interações entre os elementos naturais e humanos.

No campo das ciências geográficas, a paisagem sempre ocupou um lugar de destaque apresentando-se como um importante instrumento de análise e interpretação da realidade. Tendo em vista que as concepções de paisagem vinculam-se a pensamentos associados ao cenário histórico e cultural de diversas épocas e lugares e dada a ressignificação do seu conceito ao longo da história do pensamento geográfico, podemos afirmar que a discussão sobre a categoria paisagem assume importância no entendimento da institucionalização da Geografia como ciência.

Segundo Vitte (2007, p. 72), a temática relativa ao conceito de paisagem e seu tratamento na Geografia, acumula ao longo dos tempos uma série de polêmicas envolvendo 


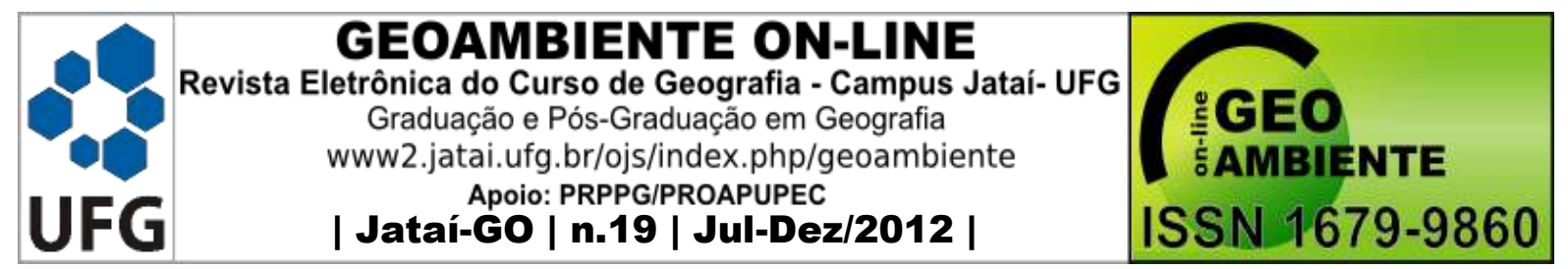

uma enorme diversidade de conteúdos e significados. Para o autor, "esta elasticidade demonstra, na realidade, complexificação do conceito, em função de como o mesmo foi tratado pelas várias correntes na Geografia, moldadas cada qual em um determinado contexto histórico e cultural".

Considerando que várias concepções filosóficas e visões de natureza influenciaram as pesquisas sobre a paisagem, destaca-se a evolução do conceito de paisagem do pensamento que via a natureza como condição para o desenvolvimento de uma determinada sociedade ao pensamento que busca tratar o ser humano como parte integrante da natureza.

Nesse sentido, partindo-se do entendimento de que o conceito de natureza está ligado ao estágio de desenvolvimento científico e tecnológico tem-se que na visão moderna ocorreu uma verdadeira separação entre o homem e a natureza. Conforme Melo e Souza (2009, p. 150) na concepção moderna, as vertentes do antropocentrismo e tecnocentrismo incidem de forma a tratar a natureza enquanto "máquina regida por leis externas a si mesma, logo, passível de regulação e de completo domínio pelo homem”.

Mezzomo (2010, p. 02) coloca que "a partir dos séculos XVI e XVII, a natureza passa a ser vista, cada vez mais, como recurso, motivada principalmente pela revolução técnicocientífica que a distanciou da interpretação do divino", tornando-a objeto de conhecimento e transformação. Bernardes e Ferreira (2003, p. 17) destacam que isso se refere a compreensão tradicional das relações entre o homem e a natureza desenvolvidas até o século XIX que considerava ambos como pólos excludentes, "tendo subjacente a concepção de uma natureza como fonte ilimitada de recursos à disposição do homem, sendo incorporada como um objeto a ser possuído e dominado”.

No século XX até os dias atuais, reivindica-se uma maior interação entre a natureza e a sociedade. Nos estudos da Geografia o tratamento dado à interação entre os aspectos sociais e naturais sempre foi motivo de discussão. Abordando a construção da Geografia com base no conceito de ambiente, Suertegaray (2002, p. 118) afirma que no início buscava-se uma interação homem X meio, meio como sinônimo de natural e o homem era entendido como externo ao meio, ou externo à natureza. "Ao longo do tempo, a Geografia vai transformando sua compreensão e passa a pensar o ambiente como homem/sociedade e seu entorno. $\mathrm{O}$ homem não só está envolvido pelos “objetos e ações”, mas envolve-se com eles, numa integração conflitiva". 


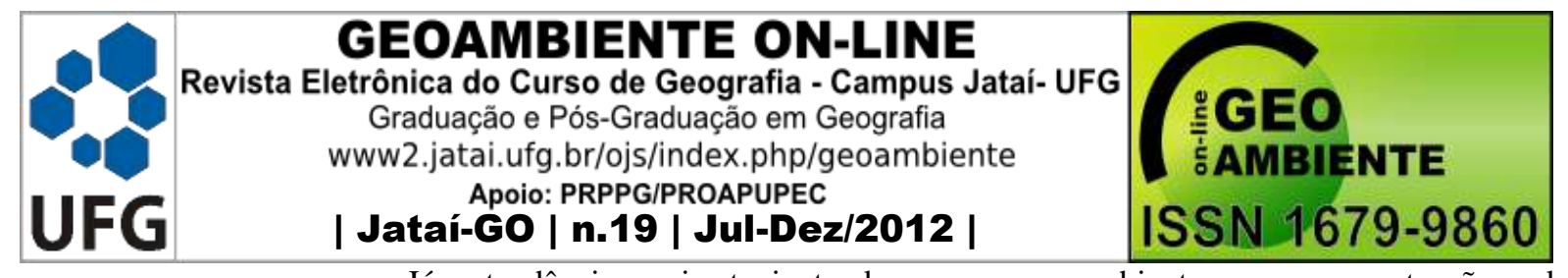

Já as tendências mais atuais, tendem a pensar o ambiente sem negar as tensões sob suas diferentes dimensões. E, na perspectiva da Geografia, retoma-se um pensamento conjuntivo, onde o meio ambiente vai sendo pensado como ambiente por inteiro, na medida em que em sua análise exige compreensão das práticas sociais, das ideologias e das culturas envolvidas (SUERTEGARAY (2002, p. 118).

Nos estudos sobre as bases teóricas e metodológicas da Geografia denominada de física, é fundamental o entendimento da influência da concepção sistêmica no desenvolvimento de análises integradas da paisagem. Com o surgimento da Teoria Geral dos Sistemas Dinâmicos, publicada pelo biólogo austríaco Ludwig Von Bertalanffy, em 1948, influências e avanços científicos de cunho teórico e metodológico foram desencadeados.

Com a abordagem sistêmica novas perspectivas de análise baseadas numa maior integração entre os elementos componentes da paisagem começaram a fazer parte dos estudos, caracterizando uma nova produção do conhecimento geográfico. Segundo Maciel e Lima (2011, p.164), “observou-se uma nova reflexão sobre as pesquisas da paisagem, valorizando mais os sistemas físicos, onde todos os elementos faziam parte da natureza, dando menos ênfase à vegetação, deixando de lado o aspecto fisionômico" contrapondo-se a abordagem estético-descritiva levando à compreensão dos sistemas naturais a partir da sua estrutura e funcionamento.

Entretanto, antes mesmo de o conceito de paisagem se direcionar para a abordagem sistêmica, destacam-se no século XVIII definições de paisagem com valorização do ambiente físico com significado pictórico. Conforme Manosso (2005, p. 03), é só a partir do século XIX que as definições de paisagem deixam de abarcar exclusivamente uma acepção pictórica, marcada pelo sentido estético, pela expressão da pintura e pelo desenvolvimento do paisagismo, e passam a incorporar um significado científico, "sobretudo, na Geografia, que começa a usar o termo para definir um conjunto de formas que caracterizam um determinado setor da superfície terrestre".

Na ciência geográfica diferentes abordagens sobre o desenvolvimento e aplicação do conceito de paisagem vão ser adotadas por várias escolas com paradigmas distintos, podendo variar, conforme Guerra (2006, p. 102), da abordagem estético-descritiva mais relacionada a sua gênese, "onde surgem e culminam as primeiras ideias físico - geográficas sobre os fenômenos naturais", a uma abordagem mais científica atrelada "ao desenvolvimento e estabelecimento do conceito de como vem sendo construído desde então, com influência de outras ciências, definindo-se como Ciência da Paisagem, até os dias atuais". 


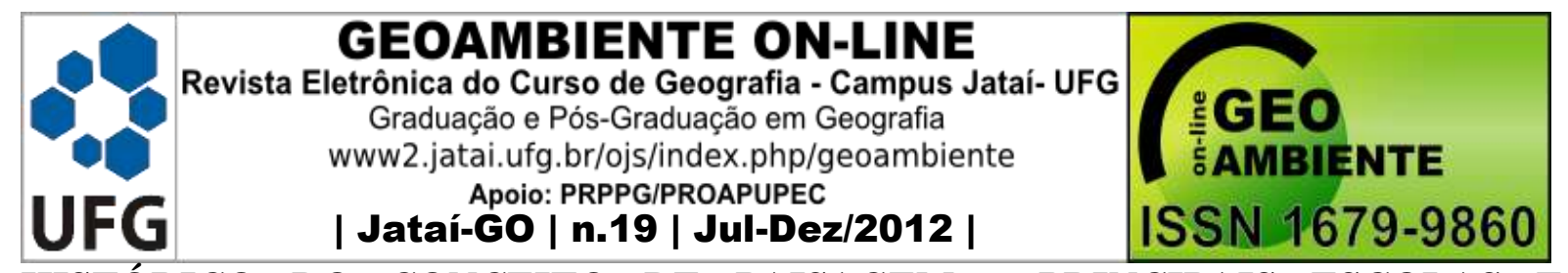

HISTÓRICO DO CONCEITO DE PAISAGEM - PRINCIPAIS ESCOLAS E ABORDAGENS

Historicamente, é no século XIX, com a escola germânica, que há o surgimento das primeiras ideias e definições acerca da paisagem. É com os trabalhos de naturalistas alemães que se estabelecem as formulações do conceito de paisagem como significado científico. Alexander Von Humboldt destaca-se como um dos precursores no desenvolvimento de uma noção de paisagem, apresentando de forma coerente uma abordagem descritiva e morfológica da estrutura da superfície terrestre, com ênfase nas relações entre elementos físicos e na fisionomia e funcionalidade da natureza.

Além de Humboldt, outros alemães como Ferdinand von Richthofen, Sigfrid Passarge, Alfred Hettner e Carl Troll, contribuíram com bases teóricas para o desenvolvimento dos estudos sobre a paisagem. Segundo Bolós (1992, p. 14), Ferdinand von Richthofen, discípulo de Humboldt, apresenta no século XX "a visão da superfície terrestre como a interseção das diferentes esferas: litosfera, atmosfera, hidrosfera e biosfera e ajuda a compreender as interconexões em qualquer setor da mesma”. Sigfrid Passarge através dos seus estudos realizados no continente africano é considerado o primeiro autor a publicar um livro sobre paisagem (Grundlagem der Landschaftskunde, 1919/1920), seus estudos consideram o caráter global e integrado da paisagem. Alfred Hettner, preocupando-se com questões metodológicas contribui através da busca pela globalidade total da paisagem por meio da inclusão do homem no sistema, face à interrelação dos fenômenos naturais com os humanos.

Já Carl Troll, geógrafo e ecólogo, foi quem aproximou a paisagem das concepções da Ecologia introduzindo o conceito de Ecologia de Paisagem em 1938 descrita como uma nova disciplina resultante da interseção da Geografia Física e a Ecologia que contempla uma perspectiva espacial, geográfica, para entender os fenômenos naturais complexos (BOLÓS, 1992).

A escola soviética no final do século XIX também inicia seus estudos sobre a paisagem (Manosso, 2005, p. 03) sendo clara e de fundamental importância a contribuição de V. V. Dokoutchaev, pedólogo russo tido como o fundador da Nova Escola Geográfica Soviética. Para Dokoutchaev o solo é o resultado da interação entre os elementos da paisagem. "Nesse momento são formulados os fundamentos da pedologia, apoiados na noção de Complexo Natural Territorial” (MOURA e SIMÕES, 2010). 


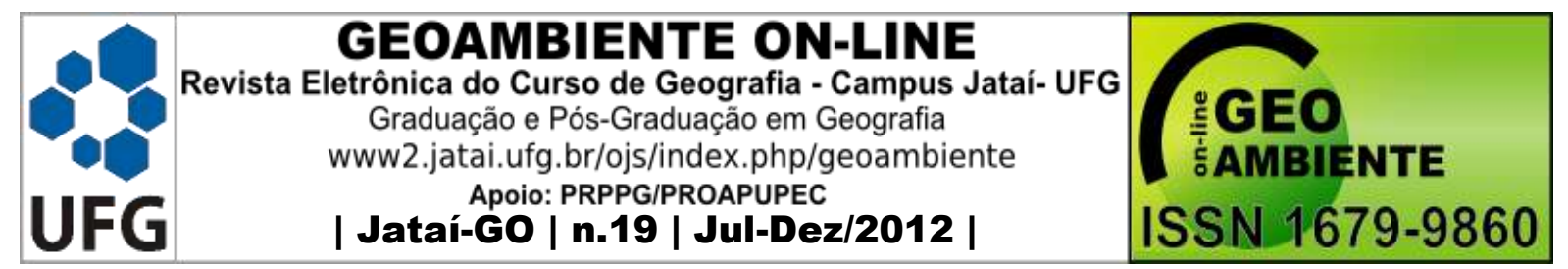

Os estudos da Geografia soviética tiveram grande destaque no desenvolvimento da

Ciência da Paisagem sendo de grande relevância a contribuição de Viktor Borisovich Sotchava, especialista siberiano, que em 1960, utiliza os princípios da Teoria Geral dos Sistemas e formula o método denominado geossistema. Os geossistemas são uma classe peculiar de sistemas dinâmicos abertos e hierarquicamente organizados e correspondem a fenômenos naturais que englobam os fatores econômicos e sociais, os quais influenciam na estrutura e peculiaridades espaciais (SOTCHAVA, 1978).

Segundo Ross (2006, p. 25), tais fatores devem ser considerados nos estudos/pesquisas dos geossistemas, pois têm tem influência sobre as mais importantes conexões dentro de cada geossistema, sobretudo nas paisagens fortemente modificadas pelo homem. Para o autor, também são importantes na classificação do geossistema a dinâmica e o enfoque genético.

Qualquer geossistema se encontra em um determinado estado de dinâmica, no qual as estruturas primitivas, as mudanças de estado e as funções de determinado componente são fundamentais para o seu entendimento e classificação. A classificação do geossistema deve revelar a tendência dinâmica do meio natural, mostrando as possibilidades do ótimum natural diante das sociedades humanas. A reconstrução dos ambientes paleogeográficos, para entender a dinâmica do presente e estabelecer a classificação em função da perspectiva futura da evolução de cada geossistema (ROSS, 2006, p. 26).

No entender de Passos (2006), a escola russa (Landschaftovedenie) evoluiu e da combinação do Complexo Territorial Natural com a "ação antrópica" surgiu o Geossistema. Conforme Ross (2006, p.14) é no âmbito da Geografia Física aplicada dos russos que se encontra uma preocupação crescente de arrolar a relação sociedade-natureza trabalhada na Geografia.

De acordo com Frolova (2007), na Rússia, durante todo o século XX pontos de vista opostos vão coexistir e servir para a resolução dos diversos problemas.

Os geógrafos da paisagem vão hesitar entre uma abordagem que totaliza, segundo a qual o homem faz parte da paisagem que transforma, e uma abordagem dualista, segundo a qual o homem representa uma força externa à paisagem. Desde a invenção da paisagem científica, as perguntas sobre sua continuidade ou sua descontinuidade e o dualismo ou o globalismo da abordagem da paisagem serão tratados de maneiras diferentes (FROLOVA, 2007, p. 163).

Para Frolova $(2007,167)$, é nesse período que surge uma nova concepção que visa resolver esses problemas metodológicos. Apoiada sobre a teoria sistêmica, "a doutrina dos geossistemas, proposta nos anos 1960-1970 por Sotchava, teve por base uma ideia de rota 


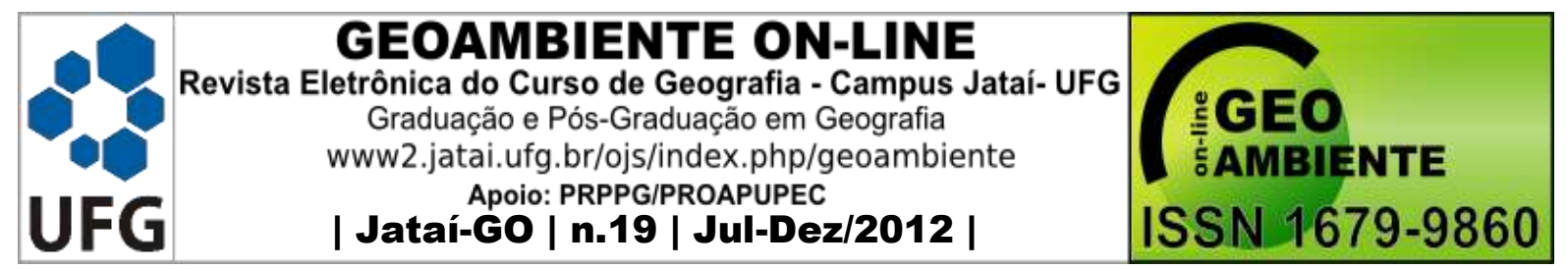

absoluta entre todos os "componentes" da paisagem que, devido à sua interação, lhe dão um sentido".

Assim é que foram de fundamental importância à Ciência da Paisagem, os estudos da Geografia soviética, uma vez que daí surgiram estruturas institucionais dedicadas a várias especializações, sendo ainda mais importantes as contribuições de ordem epistemológica, que ajudaram a difundir os trabalhos de Sotchava para além da antiga URSS e dos países do leste europeu (MOURA e SIMÕES, 2010).

Semelhante aos estudos da paisagem das escolas germânica e russa, outras escolas como a anglo-saxônica e a francesa também tiveram destaques. Segundo Bolós (1992) as contribuições anglo-saxônicas foram fundamentais para o desenvolvimento da Ciência da Paisagem, destacando-se os trabalhos de Smuts, cuja teoria do Holismo foi essencial para a compreensão do conceito de integração da paisagem e a figura de "A. G. Tansley, com a proposição do termo "ecossistema" que juntamente com os alemães Ernest Haekel, biólogo, fundador da Ecologia, e Carl Troll, geógrafo, criador do termo Ecologia de Paisagem, contribuíram para aproximar a Ecologia da Geografia e desenvolver a busca pela compreensão geoecológica da paisagem, muito difundida a partir das últimas décadas do século XX".

Ross (2006, p. 29) destaca que o suporte teórico de geossistema, tanto para os russosoviéticos como para os franceses, está na noção da "paisagem ecológica", introduzida por Troll a partir do final da década de 1930 e na ampliação do termo e conceito de ecossistema de Tansley em 1935, que se desenvolveram nas décadas de 1940/1950 e alavancaram a Geografia Física dos russos e franceses nas décadas seguintes.

No tocante a escola francesa, os trabalhos do biogeógrafo George Bertrand e do geomorfólogo Jean Tricart, tiveram grande influência nos estudos sobre a paisagem. A partir da década de 1960, a concepção sistêmica é adotada na França e os estudos desses dois autores se destacam como os mais característicos da produção recente da Geografia Física a partir do estabelecimento de abordagens e propostas teórico-metodológicas próprias bastante úteis para classificação da paisagem.

Tricart em 1977 publica a obra Ecodinâmica e lança as bases para o delineamento da Ecogeografia ou Geoecologia. Bertrand em "Paisagem e Geografia Física Global: esboço metodológico", publicada em 1968, expõe suas ideias sobre paisagem e geossistema alargando a discussão sobre esses temas em diversos países como no Brasil. Conforme 


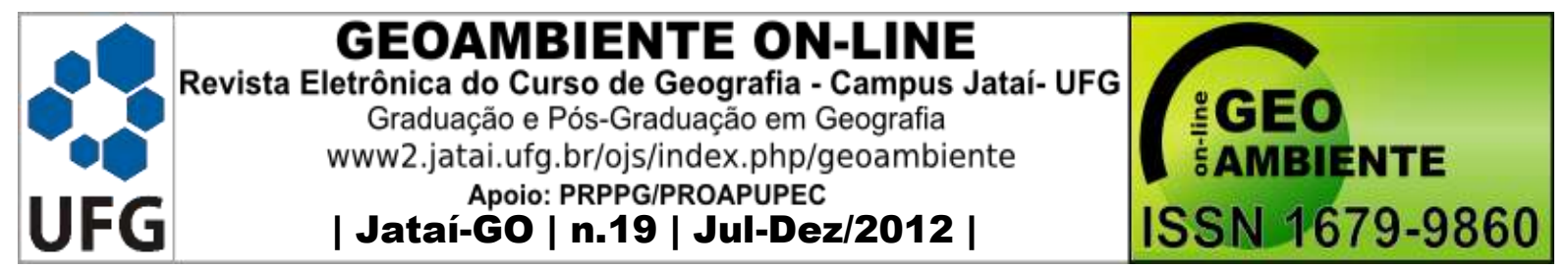

Cavalcanti (2004, p. 106) "com a contribuição de Bertrand (1978) surgiram as bases metodológicas para a utilização dos conceitos de paisagem em estudos de Geografia Física".

A proposta de Bertrand define o geossistema como um "conceito territorial, uma unidade espacial que pode ser delimitada e analisada" (Nascimento e Sampaio, 2005), em função da escala de tratamento das informações (Ross, 2006). A abordagem geossistêmica considera as variações paisagísticas como produto histórico dos fluxos de matéria e energia, abarcando a ação do homem. Como características deste modelo têm-se as relações dinâmicas entre os elementos, as trocas de matérias e energia dentro do sistema, organização espacial marcada por conexões sistêmicas que torna possível o entendimento da estrutura, do funcionamento interativo do conjunto, da dinâmica do meio natural, das possibilidades do ótimum natural diante das sociedades humanas.

No tocante a definição de Sotchava para geossistema, alguns autores tecem críticas principalmente quanto à metodologia de classificação das paisagens naturais adotada que se utiliza de escalas de grande magnitude, o que dificultaria a associação com a escala socioeconômica.

Sobre isso, Nascimento e Sampaio (2005, p. 169) destacam como limitações a ausência de uma maior precisão espacial em sua definição e o seu caráter pouco dialógico. "Sotchava ao formular a Teoria dos Geossistemas, classifica as paisagens naturais com critérios biogeográficos, em homogêneas ou diferenciadas em três níveis: planetário, regional e topológico, sendo que qualquer desses níveis pode ser chamado de geossistema, sem maiores critérios".

É nesse contexto que segundo os autores, "Bertrand, em 1968, otimiza tal classificação atribuindo uma melhor hierarquia das paisagens com uma tipologia às ordens taxionômicas do relevo, ao prisma de uma perspectiva espaço-temporal, em um esboço sobre uma Geografia Física Global", definindo de uma parte os (Taxons) Unidades Superiores (Zona, Domínio e Região Natural) e de outra parte os (Taxons) Unidades Inferiores (Geossistemas, Geofácies e Geótopo).

Contudo, para Ross (2006), nesse esforço inicial de Bertrand para definir, caracterizar e classificar as unidades de paisagem e, por conseguinte, os geossistemas, surgiu uma certa confusão em estabelecer, sobretudo, os níveis taxonômicos. 


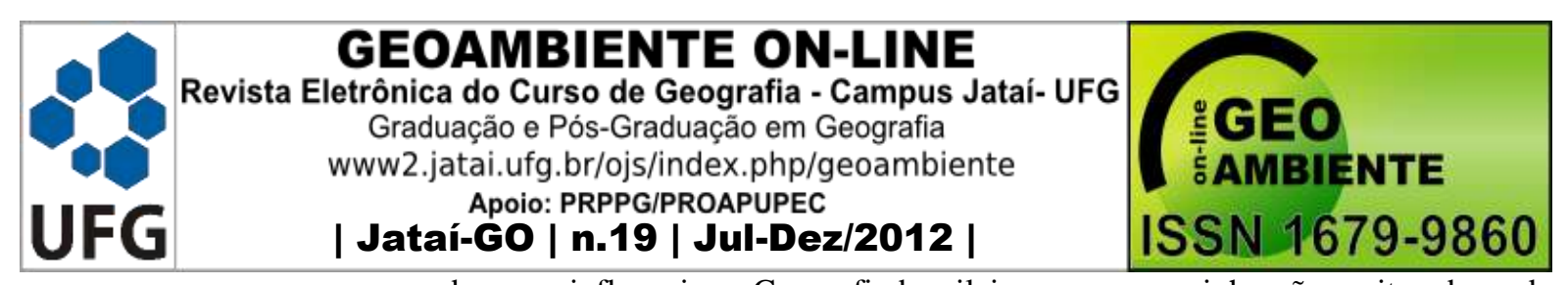

acabou por influenciar a Geografia brasileira por um caminho não muito adequado, pois se difundiu a concepção de que o geossistema como categoria de análise era também um nível de classificação dentro de um conjunto de seis táxons. Ao se tentar aplicar tal proposição, e ao mesmo tempo representá-la cartograficamente, resultavam grandes dificuldades de se estabelecer o que de fato poderia ser um geossistema, um geofáceis ou um geótopo, ou, dependendo da escala de representação, podia-se confundir geossistema com domínio, região natural e assim por diante (ROSS, 2006, p. 31).

Apesar das críticas, Bertrand, ao se debruçar sobre a Teoria dos Geossistemas (Figura 1), traz uma contribuição mediante a proposição de uma metodologia que estuda integradamente os elementos do potencial ecológico, exploração biológica e atividades socioeconômicas e culturais permitindo introduzir uma dimensão temporal e uma perspectiva evolutiva na análise da paisagem.

Figura 01. Geossistema. Fonte: Bertrand, 2004.

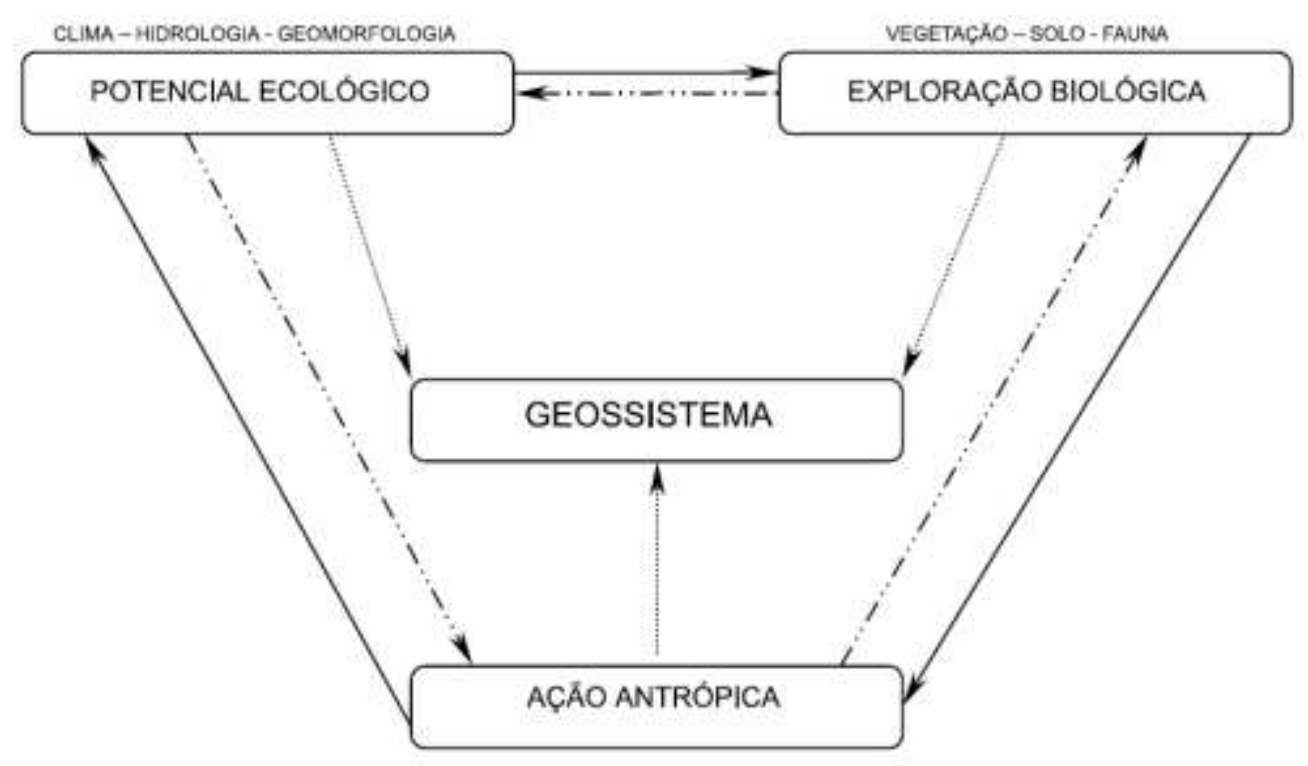

Esse aparato metodológico incentiva o advento de estudos integrados das paisagens. Assim, o geossistema, ao pregar uma linha teórico-metodológica que se debruça sobre a perspectiva sistêmica permitindo análises espaço-temporais sustentadas na estrutura, funcionamento e dinâmica dos sistemas, passa a ser de grande valia para os estudos ambientais uma vez que favorece a síntese da paisagem tão fundamental ao geógrafo. 


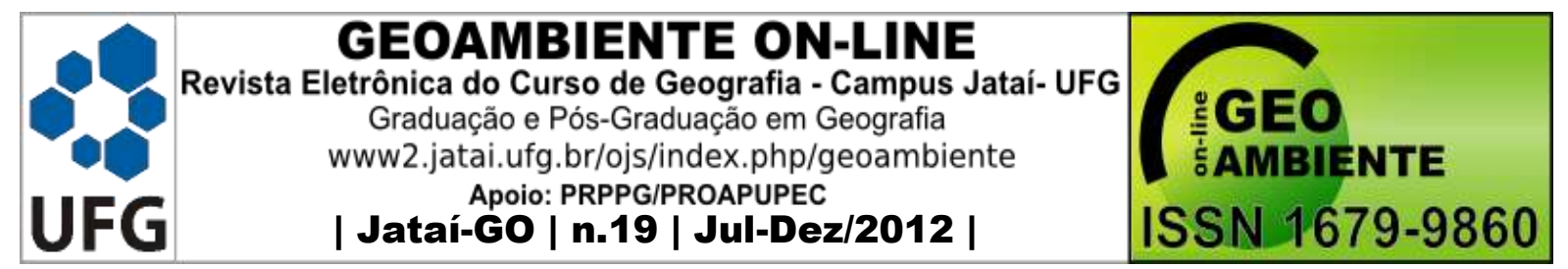

A geografia física ao adotar a perspectiva analítica sistêmica encontra um caminho promissor sólido para o estudo da complexidade e dinamicidade das organizações espaciais, a partir das relações sociedade-natureza (abordagem integrada).

\section{INFLUÊNCIA DO MÉTODO GEOSSISTÊMICO NOS ESTUDOS INTEGRADOS EM GEOGRAFIA FÍSICA}

No tocante à integração entre elementos naturais e humanos na análise da paisagem, é importante considerar que o conceito de paisagem nas duas primeiras décadas do século XX estava atrelado à herança do naturalismo "sem envolver uma definição mais integradora e abrangente dos sistemas físicos e sociais" (Maciel e Lima, 2011, 163). Essa visão é voltada para uma acepção de cunho "fortemente natural" (Rodriguez e Silva, 2002, p. 96), sendo marcada por trabalhos direcionados "à sistematização, taxonomia e descrição da vegetação".

Esse enfoque morfológico, nos dizeres de Guerra (2006, p.103), "perdura até aproximadamente a década de 20 do século XX, quando então começa a incorporar uma reflexão mais integradora entre as partes que compõem a paisagem, contrapondo-se à estéticodescritiva, sendo o período que se segue marcado pela Teoria Geral dos Sistemas, que incorpora uma nova orientação aos estudos da paisagem sob uma perspectiva sistêmica e dinâmica entre os componentes da natureza".

Christofoletti (1999) assinala que, nas duas primeiras décadas do século XX, há uma tendência maior para as descrições dos aspectos dos elementos físicos das paisagens (destacando-se as formas topográficas), em relação aos aspectos das atividades socioeconômicas (com destaque para as paisagens rurais). Ou seja, o referido autor aponta que o conceito de landschaft é visto como o de unidade territorial, aproximando-se muito do que Dokoutchaev definia para seu "Complexo Natural Territorial", e destaca que a valorização maior em focalizar as paisagens morfológicas e da cobertura vegetal abre caminho para se estabelecerem distinções entre as paisagens naturais e paisagens culturais.

Quanto à geografia física, para Mendonça (1989, p. 34) prevaleceram nos primeiros 50 anos do século XX estudos individualizados dos aspectos do quadro natural do planeta, distantes da geografia humana. Conforme o autor, "se no estudo da geografia a relação entre o homem e a natureza aparece como objetivo, a geografia física de influência demartoniana ${ }^{1}$

\footnotetext{
${ }^{1}$ De Martonne, geografo francês, que com a obra Tratado de Geografia Física Global influenciou toda a produção francesa e de outros países onde se desenvolviam estes estudos até meados da dec de 50. Dissociada dos aspectos humanos da geografia a obra reuniu em alguns capítulos os quatro ramos principais da geografia
} 


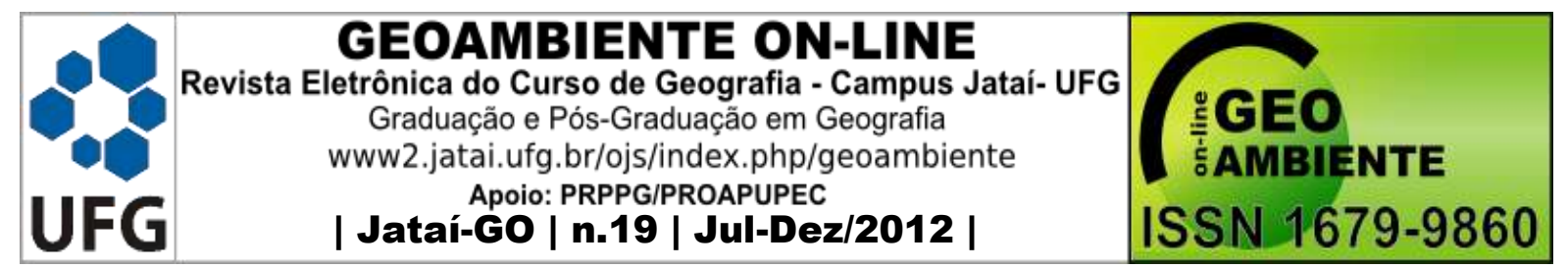

esteve longe destes propósitos, servindo como mero auxiliar de suporte a geografia humana em alguns estudos de caso".

Com a perspectiva sistêmica uma nova produção do conhecimento geográfico passa a se manifestar a partir de novas perspectivas de análise baseadas numa maior integração entre os elementos componentes da paisagem. Rodriguez e Silva (2002, p. 93), destacam que este conceito integrador expressava "nova visão da geografia física em contradição com a visão tradicional da análise isolada dos componentes naturais", que não permitia a interpretação das influências mútuas entre os componentes naturais, empreendidos sob uma visão metafísica e mecanicista.

É nesse contexto, que a partir da década de 60 do mesmo século surge o geossistema como concepção metodológica que possibilita estudar os fenômenos naturais sem excluir os fatores econômicos e sociais das paisagens modificadas pelo homem traduzindo-se como um importante instrumento de análise geográfica. Cavalcanti (2004) assinala que com o surgimento do geossistema como método específico para os trabalhos da Geografia Física foi possível a definição das relações entre seus elementos componentes, tomando-se como denominador comum a questão natural sob a ótica antropocêntrica onde as atividades humanas e econômicas descaracterizam e modificam suas relações internas.

Entretanto, Ross (2006) considera que a questão do antrópico na abordagem geossistêmica desde o inicio foi insuficientemente tratada.

O desenvolvimento e aplicação da abordagem geossistêmica começaram com os trabalhos de Sotchava para a região da Sibéria, onde a ocupação era rarefeita. Ao ampliar-se sua aplicação para outras áreas do planeta onde as alterações promovidas na natureza eram maiores e a densidade ocupacional mais intensa, defrontou-se com o problema, pois, dentro da abordagem naturalista do geossistema, o antrópico tem sido tratado muito como o elemento modificador das características físico-biológicas e quase nada se fez além de uma avaliação desses impactos (ROSS, 2006, p. 35 )

Estudos baseados na abordagem geossistêmica passam a ser desenvolvidos por muitos geógrafos físicos e adotados como referência no procedimento de compreensão das paisagens abrindo caminho para uma maior reflexão sobre a ideia do conceito de paisagem como a relação homem-natureza. É nesse sentido que concordamos com Nascimento e Sampaio (2005) quando colocam que apesar de perdurarem problemas e intermináveis discussões sobre

física tendo em vista o aparecimento dos ramos específicos representados pela climatologia, geomorfologia, biogeografia da hidrografia, etc. os quais influenciaram o conhecimento geográfico produzido a partir de então (MENDONÇA, 1989, p. 34). 


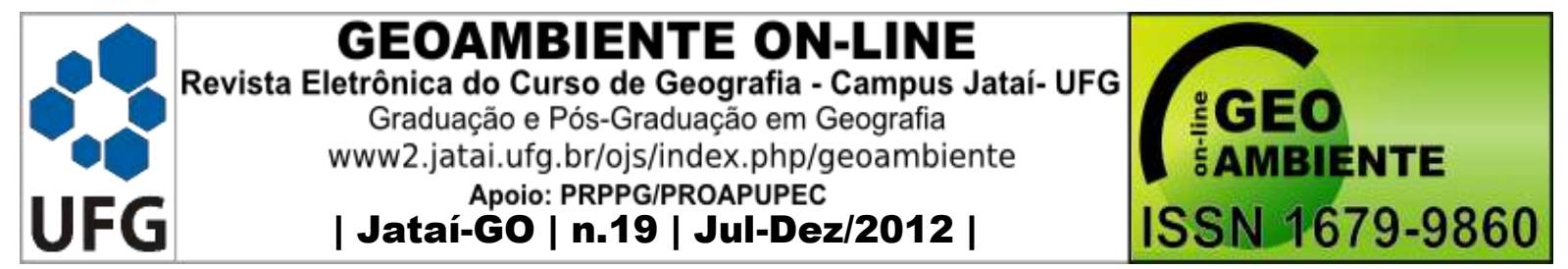

a aplicabilidade da Teoria dos Sistemas em Geografia, apesar das críticas ao geossistema tendo sido taxado como neopositivista deve-se reconhecer que, não se conseguiu desenvolver outro método que viesse a substituí-lo, como forma de adequação metodológica, sobretudo como uma unidade sistêmica para descrever a paisagem.

É um avançar de pensamento que de acordo com Guerra (2006), permitiu o surgimento de novas técnicas de análises científicas e ajudou a entender que os elementos da natureza, além de relacionarem-se entre si, formam também um todo unitário e complexo e que os sistemas que compõem a natureza e os socioeconômicos possuem comportamentos irregulares onde suas relações podem ser previsíveis ou não ao considerar a possibilidade de ruptura, irreversibilidade, imprevisibilidade das mudanças e de auto-regulação dos sistemas abertos mediante os seus estados de estabilidade temporais.

A partir das duas últimas décadas do século $\mathrm{XX}$ os estudos sobre a paisagem se intensificam. Os trabalhos de Bolós (1981) são exemplos da aplicação do geossistema e se destacam pela consideração da estrutura geoecológica da paisagem composta pelos elementos bióticos e abióticos associados aos sistemas socioeconômicos promovidos pela ação antrópica e que exerce forte influência sobre a paisagem. Para Bolós (1981), a paisagem, em sua abordagem sistêmica e complexa, será sempre dinâmica e compreendida como o somatório das inter-relações entre os elementos físicos e biológicos que formam a natureza e as intervenções da sociedade no tempo e no espaço, em constante transformação.

Bolós (1981, p. 55), define a paisagem integrada como "uma área geográfica, unidade espacial, cuja morfologia agrega uma complexa inter-relação entre a litologia, estrutura, solo, fauna e flora, sob ação constante da sociedade, que transforma". Sendo que o espaço geográfico é onde as intervenções da sociedade alteram-se ao longo do tempo e sua dinâmica e evolução são determinadas por processos históricos e naturais.

Para Monteiro (2000), apud Ross (2006, p. 35) a integração antrópica nos geossistemas deve ser considerada em função de variantes importantes, configurando o trinômio: a extensão do território focalizado, o que conduz a escolha da escala de abordagem; a duração histórica da ocupação humana e sua importância processual no jogo de relações do geossistema (tempo) e o grau de intensidade sob o qual se manifestam as ações antropogênicas em suas relações com as diferentes partes em que se subdividem os geossistemas (estrutura interna e dinamismo funcional). 


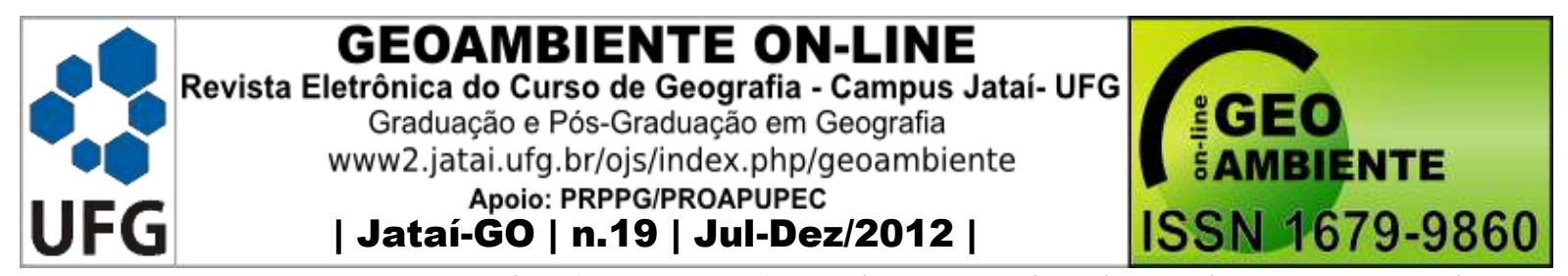

De acordo com Monteiro (2001, p. 48), "a demonstrada relevância para os estudos das relações homem-natureza e avaliação da qualidade ambiental, bem como o aprimoramento como veículo para aplicação da Geografia no planejamento são possibilidades para as quais estão direcionadas as premissas teóricas". Para o autor, a aplicação do método geossistêmico auxilia no diagnóstico qualitativo podendo-se com isso avançar na prognose tão necessária no planejamento ou ordenação territorial.

Discorrendo sobre trabalho realizado na Bahia referente à caracterização da qualidade ambiental, Monteiro (2001, p. 81) esclarece a divisão do tratamento geossistêmico em 4 etapas: Análise; Integração; Síntese e Aplicação. O tratamento geossistêmico visa a integração das variáveis naturais e antrópicas (considerada etapa Análise), juntamente com a segunda etapa (Integração), em que se fundem os recursos, os usos e os problemas que são configurados em unidades homogêneas (etapa Síntese) e assumem um papel primordial na estrutura espacial, conduzindo assim, para a etapa conclusiva que se refere ao esclarecimento do estado real da qualidade do meio ambiente (etapa Aplicação).

Outro autor que utiliza a concepção geossistêmica nos seus estudos é Passos (2006). Aborda o geossistema como uma abstração, um conceito, um modelo teórico da paisagem inacabado e assinala que o sistema geográfico corresponde à aplicação do conceito sistema (Teoria Geral de Sistema) e à concepção sistêmica da paisagem. Conforme Passos (2003, p.09) a paisagem integra o homem, ou mais precisamente, a sociedade considerada como agente natural sendo reflexo da organização social e de condições "naturais" particulares. A paisagem é, portanto, um espaço em três dimensões: natural, social e histórica".

Tratando de contribuições metodológicas para os estudos da paisagem, Maria del Tura Bovet Pla e Jordi Ribas Vilàs (1981) propõem uma metodologia geral que abrange cinco etapas de estudos: Análise; Diagnose; Correção de Impactos Ambientais; Prognose e Síntese. Segundo Bovet Pla e Vilàs (1981, p. 128-130):

1. Análise: é a fase analítica que se constitui como o passo básico dos estudos de paisagem. Para chegar a compreender uma paisagem deve-se partir de suas características que derivam das diversas interações dos elementos que a integram. Seu nível de análise variará de acordo com as necessidades do tipo de investigação sendo a análise orientada de tal forma que se possam conhecer os elementos mais significativos, podendo-se destacar as analises da estrutura 


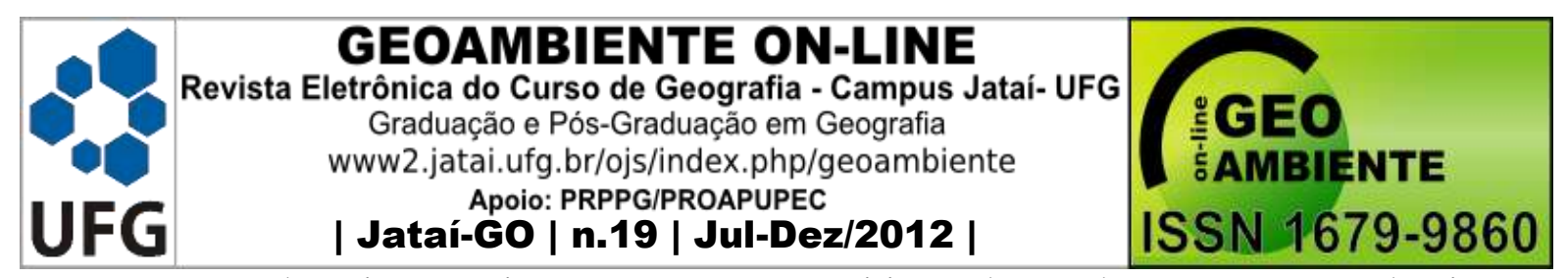

da paisagem, importantes por permitirem desvendar os processos do sistema, decifrar sua organização espacial e sua dinâmica.

2. Diagnose: é a etapa construída a partir dos resultados da Análise e requer a confecção e categorização dos dados que relacionam a estrutura natural e antrópica, podendo-se apontar dois tipos: as diagnoses descritivas e as diagnoses de potencialidade. As descritivas em geral detalham as características da paisagem, classificando-a mediante unidades homogêneas, por sua tipologia ou por seu estado dinâmico. Já as diagnoses de potencialidade são aquelas cujo objetivo é definir a aptidão ou capacidade da paisagem frente às diversas possibilidades de atuação antrópica.

3. Correção de Impactos Ambientais: possui como objetivo aplicar as medidas necessárias para tratar de eliminar, corrigir ou amenizar os desequilíbrios ou possíveis dinâmicas negativas da paisagem, detectadas na fase de diagnoses. Está geralmente relacionada ao uso indevido do potencial das unidades de paisagem.

4. Prognose: é uma elaboração científica que concebe futuros estados de geossistemas, suas propriedades fundamentais e seus diversos estados dinâmicos. Estas previsões têm em conta tanto os aspectos da evolução natural da paisagem como os aspectos sociais e econômicos que são susceptíveis de modificá-la. A prognose da paisagem concentra seu estudo nos processos e condições das mudanças que se operam na paisagem, por um lado, e nas demandas sociais, por outro. Investiga, portanto, a evolução e o desenvolvimento da paisagem, com o objetivo de propor alternativas a esta evolução.

5. Síntese: por fim, é a etapa que consiste no planejamento de técnicas preventivas adequadas para cada tipo de paisagem, segundo os resultados de sua prognose e de acordo com a gestão prevista para as ditas paisagens.

Para Christofoletti (1999), a paisagem constitui-se no campo de investigação onde se permite que o espaço seja compreendido como um sistema ambiental, físico e socioeconômico, com estruturação, funcionamento e dinâmica dos elementos físicos, biogeográficos, sociais e econômicos. Princípio estrutural, funcional e dinâmico-evolutivo são 


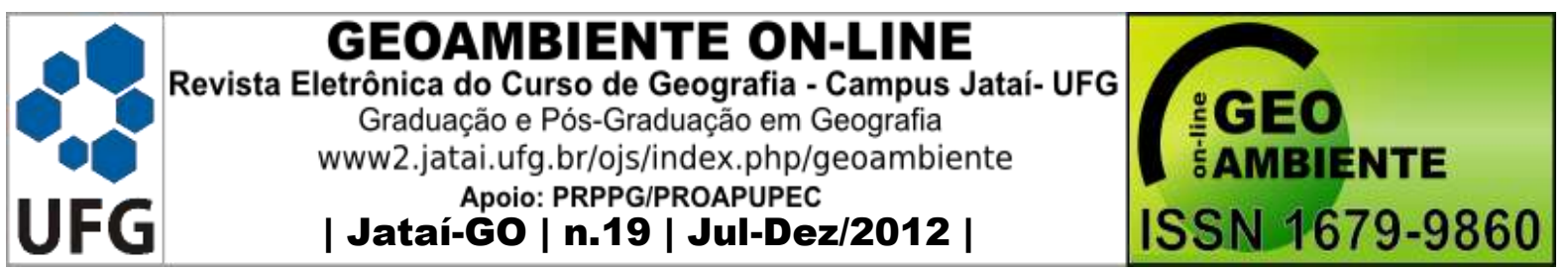

considerados por Rodriguez et. al (2004) como três dos cinco enfoques (Figura 2) de análise da paisagem que podem ser adotados nos estudos.

Figura 2: Enfoques e métodos de análise da paisagem. Fonte: Rodriguez et al 2004.

\begin{tabular}{|c|c|c|c|}
\hline PRINCIPIOS & CONCEITOS BÁSICOS & MÉTODOS & INDICES \\
\hline ESTRUTURAL & $\begin{array}{l}\text { Estruturas das paisagens: } \\
\text { monossistêmica c parassistê- } \\
\text { mica. Estrutura horizontal c } \\
\text { vertical, geodiversidade }\end{array}$ & $\begin{array}{l}\text { Cartografia das paisagens, } \\
\text { classificação quantita- } \\
\text { tiva-estruturais, tipologia } \\
\text { e regionalização }\end{array}$ & $\begin{array}{l}\text { Imagem, complexidade, } \\
\text { forma dos contornos, viżi- } \\
\text { nhança, conexão, compo- } \\
\text { siçāo, integridade, cocrên- } \\
\text { cia c configuração geoeco- } \\
\text { lógica. }\end{array}$ \\
\hline FUNCIONAL. & $\begin{array}{l}\text { Balanço de EMI, interaçĩo de } \\
\text { componentes, gênese, processos, } \\
\text { dinamica funcional, resiliència } \\
\text { e homeostase }\end{array}$ & $\begin{array}{l}\text { Análise funcional, } \\
\text { geoquimica, geofisica e in } \\
\text { vestigaçôes estacionais }\end{array}$ & $\begin{array}{l}\text { Função, estabilidade, soli- } \\
\text { dez, fragilidade, estado } \\
\text { geoccológico, capacidade } \\
\text { de auto-manutençẵo, } \\
\text { autoregulaçāo e organiza- } \\
\text { ção, equilibrio }\end{array}$ \\
\hline $\begin{array}{l}\text { DINÅMICO- } \\
\text { EVOLUTTVO }\end{array}$ & $\begin{array}{l}\text { Dinâmica temporal, estados } \\
\text { temporais, evoluçầo e } \\
\text { desenvolvimento }\end{array}$ & $\begin{array}{l}\text { Retrospectivo, estacional, } \\
\text { evolutivo e palco-geográfico }\end{array}$ & $\begin{array}{l}\text { Ciclos anuais, regimes } \\
\text { dinámicos, geomassa, } \\
\text { geohorizonte, idade e } \\
\text { tendèncias evolutivas }\end{array}$ \\
\hline $\begin{array}{l}\text { HISTÓRICO- } \\
\text { ANTROPO- } \\
\text { GÊNICO }\end{array}$ & $\begin{array}{l}\text { Antropogènese, transformação } \\
\text { c modificação das paisagens }\end{array}$ & $\begin{array}{l}\text { Histórico e análise } \\
\text { antropogénica }\end{array}$ & $\begin{array}{l}\text { Indices de antropogénesc, } \\
\text { cortes histórico-paisagisti- } \\
\text { cos, perturbaçōes, tipos de } \\
\text { modificação e transforma- } \\
\text { ção humana (paisagens } \\
\text { contemporáneas, trocas, } \\
\text { hemorobia) }\end{array}$ \\
\hline INTEGRATIVO & $\begin{array}{l}\text { Sustentabilidade geoecológica } \\
\text { das paisagens; paisagem } \\
\text { sustentável }\end{array}$ & Análise paisagistica integral & $\begin{array}{l}\text { Suporte estrutural, funcio- } \\
\text { nal, relacional, evolutivo, } \\
\text { produtivo das paisagens; } \\
\text { categorias de manejo da } \\
\text { sustentabilidade } \\
\text { da paisagem }\end{array}$ \\
\hline
\end{tabular}

Como visto, vários autores ao realizarem estudos sobre a paisagem propõem metodologias que se fundamentam na abordagem sistêmica e na compreensão da estrutura, funcionamento e dinâmica dos seus componentes resultando em análises têmporo-espaciais integradas das inter-relações sociedade-ambiente.

Dentro desse viés, ressalta-se a importância de se identificar os elementos constituintes da paisagem, sejam naturais ou humanos, a fim de analisar as características da sua composição e distribuição espacial, a dinâmica dos processos atuantes, a existência de perturbações e as mudanças resultantes das interações, visando consequentemente o entendimento do todo de forma sistêmica. 


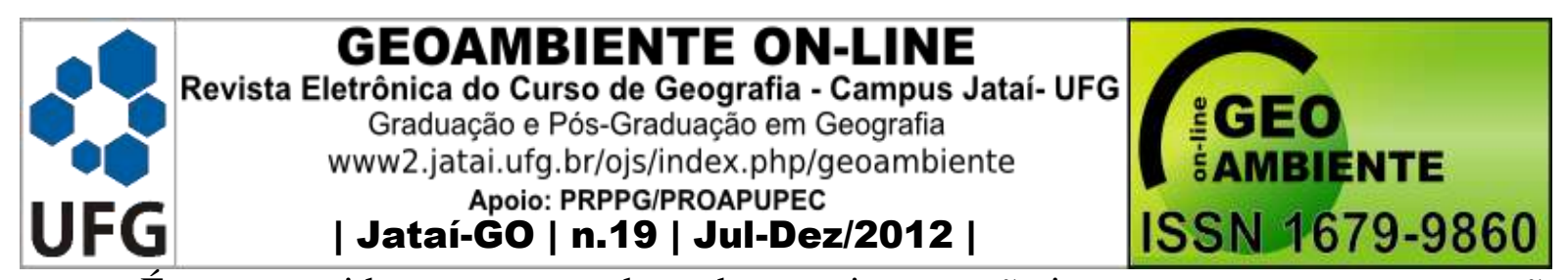

É nesse sentido que nos estudos sobre a paisagem, tão importante quanto a concepção sistêmica é a compreensão integrada a qual abrange uma ótica voltada à busca pelo entendimento dos fenômenos naturais e sociais como um conjunto indissociável passando a incorporar uma visão globalizante das interações e dinâmicas socioambientais.

Sendo assim, a perspectiva de análise integrada da paisagem é aqui considerada como uma abordagem que deve dar particular atenção à dimensão da interação sociedade-natureza, à incorporação do elemento humano, suas ações e interferências na paisagem de forma a buscar a compreensão dos fenômenos naturais e sociais no contexto das interações.

Chorley e Haggett (1974) apud Cavalcanti (2004) exploram a abundância em que a teoria dos sistemas apresenta enfoque interdisciplinar para as questões ambientais e como a metodologia dos sistemas oferece instrumento adequado para isso, verificando a maneira que as abordagens sistêmicas auxiliam no desenvolvimento de uma teoria integrada, relacionando a teoria social e econômica às teorias física e biológica.

Para Schier (2003), “o estudo da paisagem exige um enfoque integrado do qual se pretende fazer uma avaliação definindo o conjunto dos elementos envolvidos, a escala a ser considerada e a temporalidade na paisagem, levando em conta a configuração social e os processos naturais e humanos". Bolós afirma que, o objetivo do estudo da paisagem deve ser visto como uma realidade integrada, onde os elementos abióticos, bióticos e antrópicos aparecem associados de tal maneira, que os conjuntos podem ser trabalhados como um modelo de sistema.

Estudos integrados na visão de Nascimento e Sampaio (2005) são denominados de geoambientais e devem buscam uma percepção holística do meio tendo como objetivo a análise dos elementos componentes da natureza por meio de suas interconexões. Tendo em vista que o meio ambiente é formado por uma base física e biológica que se inter-relaciona de forma sistêmica e que as sociedades ao longo do tempo vêm atuando nesses sistemas ambientais de forma a interferir em sua dinâmica, há de se admitir estudos integrados visando o entendimento de como esses processos ocorrem (BARROS, 2010).

Para Ross (2006), não se trabalha com o presente e o futuro das relações sociedade natureza, sob os aspectos das fragilidades dos ambientes naturais, potencialidades dos recursos naturais, planejamento ambiental, zoneamento ambiental e gestão dos territórios dentro da abordagem ambiental, ou seja, de preservação, conservação ou recuperação ambiental, sem envolver análises sobre as questões sociais, culturais e econômicas. 


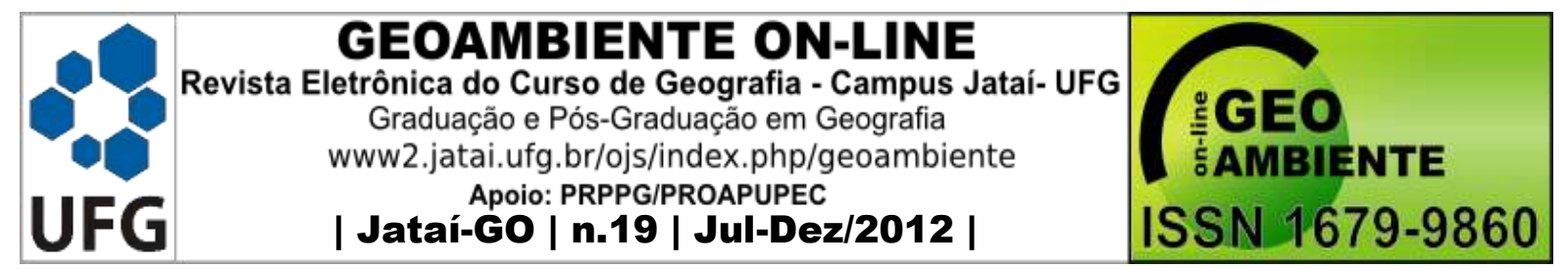

Buscando a compreensão global da paisagem, que como propõe Bertrand (2004) apenas é possível se partir da análise conjunta dos elementos naturais e sociais, os estudos da paisagem procuram focalizar o conhecimento dos limites (fragilidades) e das potencialidades (vocações) do meio permitindo assim a elaboração de diagnósticos socioambientais, zoneamentos, análises sobre tendências de evolução e dinâmica do espaço geográfico com vistas ao planejamento ambiental e gestão do território.

\section{CONSIDERAÇÕES FINAIS}

- Na paisagem há a manifestação de processos naturais e humanos, em geral, caracterizados por propriedades diversas, por ações interativas variáveis no tempo e no espaço. A ocorrência de mudanças na paisagem, sobretudo quando decorridas de atividades humanas impactantes causadoras de estados de vulnerabilidades socioambientais passam a exigir novas posturas teóricas e metodológicas;

- Nessa perspectiva, em meio à preocupação atual com a degradação ambiental a qual invoca um caráter próprio para lidar com os problemas ambientais, é que vislumbramos a importância para os estudos da Geografia Física de análises que promovam uma maior a integração entre o natural e o humano fornecendo as bases para os processos de planejamento e gestão do território;

- Tais análises devem contemplar o entendimento do funcionamento, da estrutura e da dinâmica da paisagem, sobretudo, por meio da consideração de que na abordagem da problemática ambiental o envolvimento do homem e de suas atividades deve ocorrer de modo a fazê-lo mais elemento que mero fator modificador do meio;

- A Geografia Física então se debruça na temática ambiental objetivando contribuir com a análise da paisagem mediante o estudo da organização espacial, das diversidades e complexidades naturais e sociais e assim configura um inovador rumo ante os diversos caminhos de se analisar o espaço.

\section{REFERÊNCIAS BIBLIOGRÁFICAS}

BARROS, Mariluza de Souza. Análise dos impactos ambientais decorrentes do processo de uso e ocupação da planície flúvio-lacustre e do entorno da Lagoa da Parangaba, Fortaleza. Dissertação de Mestrado (Mestrado Acadêmico em Geografia) - Universidade Estadual do Ceará, Centro de Ciências e Tecnologia. — Fortaleza. 2010. 


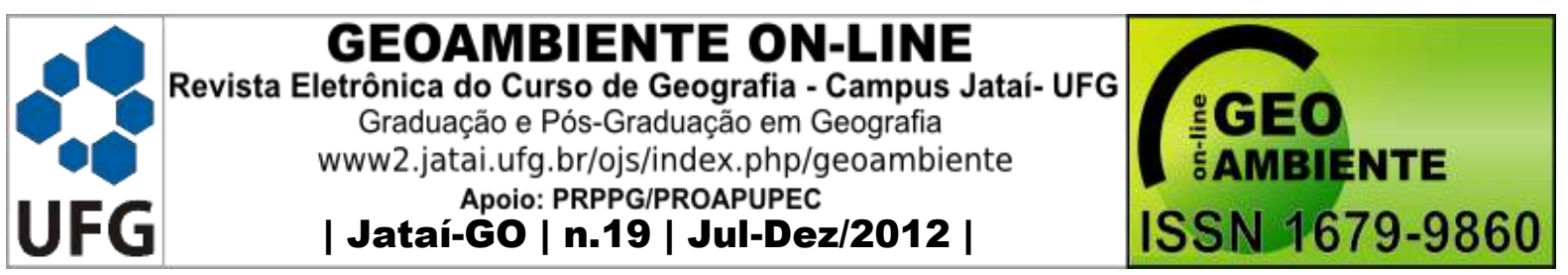

BERNARDES, Júlia Adão e FERREIRA, Francisco Pontes de Miranda. "Sociedade $e$ Natureza” In: CUNHA, Sandra Baptista; GUERRA Antônio José Teixeira (Orgs). A Questão Ambiental: diferentes abordagens. $3^{\text {a }}$ edição. Rio de Janeiro: Bertrand Brasil, 2003.

BERTRAND, Georges. "Paisagem e geografia fisica global. Esboço metodológico”. Revista RA'E GA, Curitiba, Editora UFPR. n. 8, p. 141 - 152, 2004.

BOLOS, Maria de. Manual de ciência del paisaje. Teoria, métodos y aplicaciones. Barcelona: Masson, s. a, 1992.

CAVAlCANTI, Agostinho Paula Brito. “Análise Integrada Das Unidades Paisagísticas Na Planície Deltaica Do Rio Parnaíba - Piauí/Maranhão”. Mercator - Revista de Geografia da UFC, ano 03, número 06, 2004.

CHRISTOFOLETTI, Antônio. Modelagem de Sistemas Ambientais. São Paulo. Edgard Blucher. 236p. 1999.

FROLOVA, Marina. “A paisagem dos geógrafos russos: a evolução do olhar geográfico entre o século XIX e XX”'. 168. Revista. RA`E GA, Curitiba, n. 13, p. 159-170, Editora UFPR. 2007.

GUERRA, Antônio José Teixeira e MARÇAL, Mônica dos Santos. Geomorfologia Ambiental. Rio de Janeiro: Bertrand Brasil, 2006. 192 p.

MACIEL, ANA BEATRIZ CÂMARA e LIMA, ZULEIDE MARIA CARVALHO. Sociedade e Território, Natal, v. 23, nº 2, p. 159 - 177, jul./dez. 2011.

MANOSSO, Fernando Cesar. O estudo da paisagem no município de Apucarana-PR: as relações entre a estrutura geoecológica e a organização do espaço. Dissertação de MestradoPrograma de Pós-Graduação em Geografia. Universidade Estadual de Maringá-MaringáParaná. 2005.

MELO E SOUZA, Rosemeri. "Concepções de Natureza e Tendências do Ambientalismo: Contribuições ao Debate Geográfico entre Ambiente e Paisagem no Brasil”. Geonordeste, Ano XX, n. 2. p. 133-153. 2009.

MENDONÇA, Francisco. Geografia Física: Ciência humana? Francisco Mendonça. Edição São Paulo: Contexto, 72 p. 1989.

MEZZOMO, Maristela Denise Moresco. “Considerações sobre o termo "paisagem” segundo o enfoque Geoecológico”. In: NUCCI, João Carlos (Org). Planejamento da Paisagem como subsídio para a participação popular no desenvolvimento urbano. Estudo aplicado ao bairro de Santa Felicidade - Curitiba/PR. / Curitiba: LABS/DGEOG/UFPR, 277 p. 2010. 


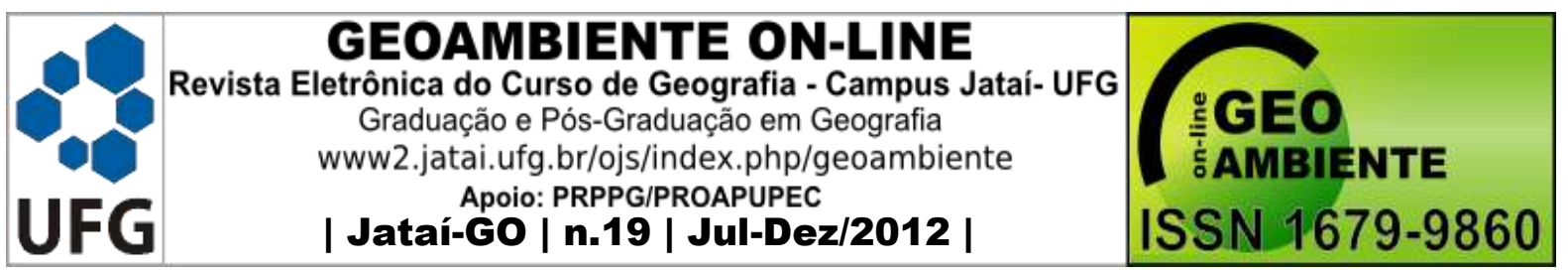

MONTEIRO, Carlos Augusto de Figueiredo. Geossistemas: a história de uma procura. São Paulo: Contexto, 2001.

MOURA, Daniele. Veleda; SIMÕES, Christian Silva. "A evolução histórica do conceito de paisagem” Ambiente \& Educação. vol. 15(1). p. 179-186. 2010.

NASCIMENTO, Flávio Rodriguez e SAMPAIO, José. Levi. Furtado. "Geografia Física, Geossistemas e Estudos Integrados da Paisagem”. Revista da Casa da Geografia de Sobral. Sobral, vol. 6/7, $n^{\circ} 1$, p. 174. 2004/2005.

PASSOS, Messias Modesto. A Raia Divisória: geossistema, paisagem e eco-história. vol. 1, Maringá, PR, Eduem, 2006.

RODRIGUEZ, José Manoel Mateo e SILVA, Edson Vicente. "Histórico da concepção das paisagens a partir de uma visão geossistêmica". Mercator - Revista de Geografia da UFC, ano 01, número 01, 2002.

ROSS, Jurandir Luciano Sanchez. Ecogeografia do Brasil: subsídios para o planejamento ambiental. São Paulo. Oficina de Textos, 2006.

SCHIER, R. A. "Trajetórias do conceito de paisagem na geografia”. Revista. RA'E GA, Editora UFPR, Curitiba, n. 7, p. $79-85,2003$.

SOTCHAVA, Viktor Borisovich. "Estudos de Geossistemas”. Métodos em Questão. N. 16, p. 1 - 52, IGEO/USP. São Paulo, 1977.

SUERTEGARAY, Dirce Maria A. "Geografia Física (?) Geografia Ambiental (?) ou Geografia e Ambiente(?)” In: MENDONÇA, Francisco e KOZEL, Salete (orgs). Elementos de Epistemologia da Geografia Contemporânea. Curitiba: Editora da UFPR, 2002.

VITTE, Antônio Carlos. "O desenvolvimento do conceito de paisagem e a sua inserção na geografia física”. Mercator - Revista de Geografia da UFC, ano 06, número 11, 2007. 